\title{
Development of a New Type of Green Switch Air Entraining Agent for Wet-Mix Shotcrete and Its Engineering Application
}

\author{
Guoming Liu ${ }^{1}$ and Lianjun Chen ${ }^{1,2}$ \\ ${ }^{1}$ College of Mining and Safety Engineering, Shandong University of Science and Technology, Qingdao 266590, China \\ ${ }^{2}$ State Key Laboratory of Mining Disaster Prevention and Control Co-Founded by Shandong Province and the Ministry of Science and \\ Technology, Shandong University of Science and Technology, Qingdao 266590, China
}

Correspondence should be addressed to Lianjun Chen; skyskjxz@163.com

Received 1 June 2016; Accepted 2 August 2016

Academic Editor: Peter Majewski

Copyright (C) 2016 G. Liu and L. Chen. This is an open access article distributed under the Creative Commons Attribution License, which permits unrestricted use, distribution, and reproduction in any medium, provided the original work is properly cited.

\begin{abstract}
Air entraining agent (AEA) can bring a lot of microbubbles into fresh concrete for improving its fluidity; however, high fluidity has adverse effect on the shootability of wet-mix shotcrete. In order to solve the contradictory issue, the paper developed a new type of green switch air entraining agent (GSAE) that can improve both the pumpability and shootability. The single-admixture and combination tests containing foaming ability and surface tension were performed with Deer agitator and automatic tension meter. The new AEA was developed with two constituents A and B. A was prepared with Sapindus mukorossi(S-1), dodecyl trimethyl ammonium chloride(1231), and polyacrylamide. B was prepared with lauryl sodium sulfate (K12) and silicone oil. The mass mix proportion was $\mathrm{S}-1: 1231$ : polyacrylamide $: \mathrm{K} 12:$ silicone oil $=1: 0.33: 0.2: 0.33: 0.47$. The application method of GSAE proposed that A was premixed with fresh concrete and then B was added at nozzle. Experimental investigation showed that the optimal mixing amount of GSAE was $0.1 \%-0.2 \%$ relative to cement. All performance measured of wet-mix shotcrete with $0.12 \%$ GSAE met the first-grade product requirements of the China National Standard. Compared with the conventional type of AEA, the proposed GSAE is capable of effectively improving pumpability and shootability.
\end{abstract}

\section{Introduction}

Wet-mix shotcrete requires the higher quality of pumpability and shootability $[1,2]$. The application of air entraining agent (AEA) can obviously improve wet-mix shotcrete pumpability due to a great number of microbubbles produced by AEA acting as lubricant balls in fresh concrete to enhance its fluidity, which can guarantee that the wet shotcrete of low water-cement ratio, owning higher slump, can be pumped successfully [3-5]. Although AEA can improve fresh concrete pumpability, high fluidity is not beneficial for concrete adhering to wall sprayed and easily causes high rebound due to dropping materials. The phenomenon influences seriously the shootability of wet-mix shotcrete. Therefore, traditional AEA cannot effectively solve both problems of pumpability and shootability simultaneously.

Many researchers mainly payed attention to the antifreeze, antipenetration, and pumpability of commercial concrete with AEA at home and abroad [6, 7]. However, the studies on wet-mix shotcrete containing AEA are relatively few, especially on the concrete shootability. Yun $[8,9]$ used an IBB rheometer to evaluate the pumpability and shootability of fresh wet-mix shotcrete with AEA and found the admixture provided a more effective way to promote the pumpability while keeping an adequate level of shootability. But it is limited to fundamental experiment study indoor. Therefore, a type of switchable AEA is necessary; in other words, the new AEA can keep active to produce microbubbles for improving fluidity of wet-mix shotcrete in the pumping process while the action should be prevented from generating foam for guaranteeing the adhesive force of concrete after spraying on wall.

Americans firstly developed the rosin type AEA In 1937, and then other types of AEA such as anionic, cationic, and nonionic surfactant AEA appeared one by one $[10,11]$. AEA that is used more in commercial concrete construction has some anionic surfactant varieties and its price is relatively higher; in particular, more chemosynthetic AEA may 
influence the environment because of being degradationresistant [12]. However, as early as the Ming dynasty in China, outstanding medical scientist Shizhen $\mathrm{Li}$ once recorded a kind of pollution-free and biodegradable surfactant "Sapindus mukorossi" in Compendium of Materia Medica that can produce abundant microbubbles and shampoo [13]. It has been used as medicine and detergent for decades [14]. Roy et al. [15] used UV-vis spectrophotometer to determine about $65 \%$ content of saponins extracted from the soapnut fruit pericarp. Mukhopadhyay et al. [16] used saponin obtained from Sapindus mukorossi or soapnut fruit for generating colloidal gas aphron dispersions to wash low levels of arsenic from an iron rich soil. In 1988, Yang $[17,18]$ invented a new type of air entraining agent with saponin firstly in China and studied the properties of fresh and hardened concrete mixed with this new AEA.

The switchable surfactants, that is to say, the surface active changes with the change of outside environment. The material that can induce the change of surfactant is commonly called "switch". According to different switchable types, it can be classified as follows: acid-base switch, photoswitch, redox switch, magnetic switch, $\mathrm{CO}_{2}$ switch surfactant, and so on [19]. Wang et al. [20] has ever compounded a kind of switchable surfactants (C18N3) that can show different actives under different PH environments. Nevertheless, the study on switchable surfactants for wet-mix shotcrete is few.

For this reason, combining with the research and development of AEA at home and abroad, in order to solve the contradictory issue between pumpability and shootability, meanwhile reducing the environmental pollution, the paper developed a new type of green switch air entraining agent (GSAE) whose main surfactant materials adopted natural saponins obtained from Sapindus mukorossi or Chinese honey locust, assisted by suds booster, foam stabilizer, and switch agent. The characteristic of shotcrete containing GSAE was also compared with other AEA in the two processes of pumping and spraying.

\section{Experimental Materials and Program}

\subsection{Experiment Materials}

2.1.1. Constituents Tested of New AEA. The compositions tested, being all analytically pure excepting saponins, were all purchased from Qingdao Jingke Chemical Co., Ltd.: lauryl sodium sulfate (K12), sodium dodecylbenzenesulfonate (LAS), sodium alpha-olefin Sulfonate (AOS), cetyltrimethylammonium chloride(1631), dodecyl trimethyl ammonium chloride(1231), alkylphenol ethoxylates (OP-10), silicone oil, and polyacrylamide.

In this work, saponins extracted from Sapindus mukorossi(S-1) or Chinese honey locust(S-2) after washing and drying had a good applicability for local raw materials. It is widespread, cheap, and easily processed [21].

2.1.2. Cement and Aggregate. Normal Portland cement (Type I) was used in these experiments with a fineness of $3180 \mathrm{~cm}^{2} / \mathrm{g}$ and a specific gravity of 3.16. No composite material is added. The coarse and fine aggregates used in the study were standard materials which comply with the requirements of the ISO standard in national standard GB/T17671-1999. Crushed gravel was experimented as coarse aggregates with a maximum size of $10 \mathrm{~mm}$. For fine aggregate, river sand was employed. The specific gravities of the gravel and river sand were 2.64 and 2.58 , respectively. The fineness moduli of the gravel and river sand were 5.70 and 2.66 , respectively. The gradation curves for both the gravel and river sand employed were along with the gradation limits recommended by ASTM C20.

2.1.3. Exiting Air Entraining Agent. Aiming to evaluate the properties of wet-mix shotcrete with GSAE, the other standard air entraining agents, $126 \mathrm{~A}$ air entraining agents from Dongguan Deep-Sea Magnesium Foaming Agent Co., Ltd., were employed for wet-mix shotcrete.

2.2. Experimental Program. The experimental scheme is shown in Figure 1. Firstly, the saponins were extracted by the way of milling and dissolution from natural plant; secondly, the new type of GSAE containing foaming constituent $A$ and switch constituent B was prepared and developed with a series of experiments; finally, the foaming constituent A was mixed with fresh concrete while the switch constituent B was added at nozzle in the field application tests.

2.2.1. Measurement of Foaming Ability. In order to simulate the alkaline environment, the following foaming experiments were carried out in the $\mathrm{Ca}(\mathrm{OH})_{2}$ saturated solution. Considering that the foam generated would be affected by various forces in different processes like stirring and pumping, the higher liquid carrying capacity of foam was required. Therefore, the method of blending foaming with Deer agitator was employed to measure foaming capacity, rather than RossMiles foaming. In the process, the temperature was kept at $20^{\circ} \mathrm{C}$. The solution prepared was stirred in a beaker with $3000 \mathrm{r} / \mathrm{min}$ speed. The foam volume, on behalf of foam capacity, was recorded after stirring for $60 \mathrm{~s}$. As time goes on, liquid separated out from foam, up to half volume of all liquid used for foaming when recording the time called "half-life period" on behalf of foam stability. The longer the half-life period is, the better the foam stability is.

The maximal diameter of foam used for measuring foam stability was also employed in the research. The foam was blown continuously by a tubule connecting a soft bottle on a glass pane. The max foam diameter was recorded momently when the foam was broken down by compressing the soft bottle. The average value of 10 times recording max diameter was finally adopted in experiments. The foam is usually small and easily broken if the film strength of a foam is low; that is, the foam stability is bad. The experiment is shown in Figure 2.

2.2.2. Measurement of Surface Tension. These solutions, owning smaller surface tension, easily produce foam for improving fresh concrete fluidity after being mixed in concrete. The surface tension of solutions was measured by the automatic 


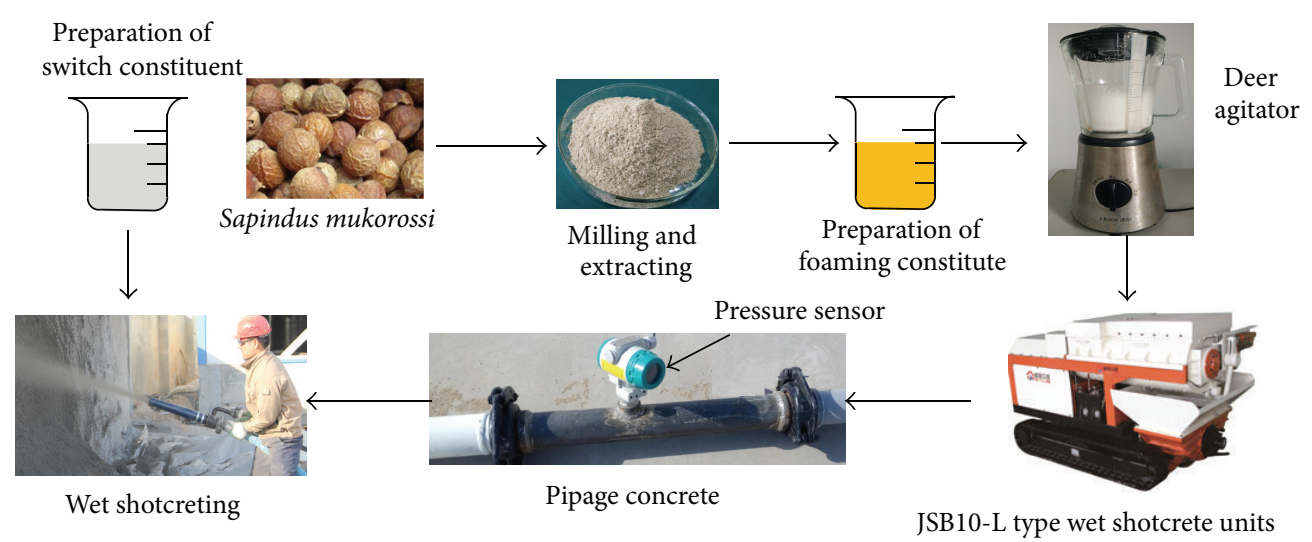

FIgURE 1: The scheme of the experiment.

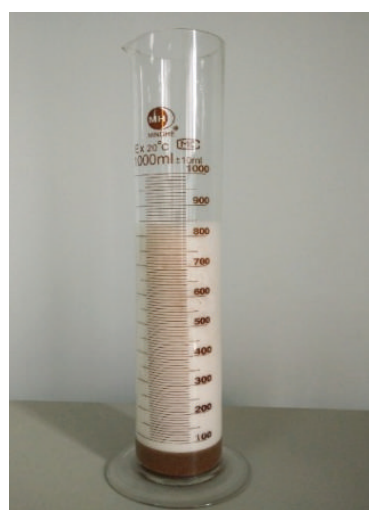

(a)

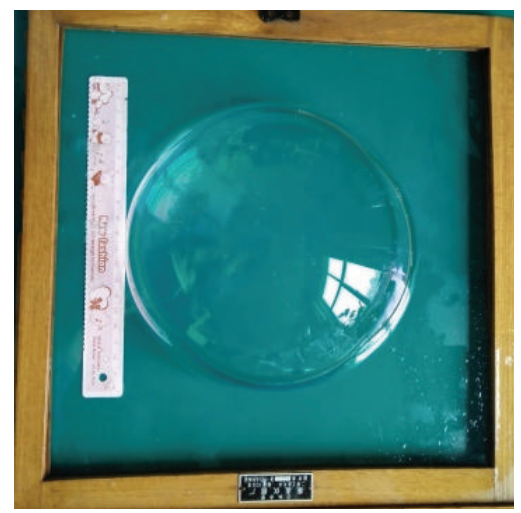

(b)

Figure 2: Tests of foaming volume (a) and maximal foam diameter (b).

tension meter (JK99B) from Shanghai Zhongchen Digital Technology Co., Ltd. at $20^{\circ} \mathrm{C}$.

2.2.3. Measurement of Pumpability and Shootability. The pumpability can be expressed indirectly by slump, the rate of pressure bleeding and pipe pressure loss,, measured, respectively, by slump cone, concrete pressure bleeding instrument, and pressure sensor. The higher the slump is and the smaller the rate of pressure bleeding and pipe pressure loss is, the better the pumpability is. The shootability can be indicated by rebound rate and the depth of one shotcrete layer. The smaller the rebound rate is and the thicker the one shotcrete layer is, the better the shootability is. All experiments were conducted according to national standard GB8076-2008 (Concrete Admixture) and GB50086-2001 (Specifications for Bolt-Shotcrete Support).

\section{Results and Discussion}

\subsection{Preparation of Foaming Constituent $A$}

3.1.1. Role and Selection of Green Foaming Monomer. The foaming monomer is a surfactant that can significantly reduce the surface tension of a solution and entrain a number of air bubbles when stirring mixed materials. Two natural foaming monomers extracted from Sapindus mukorossi(S-1) and Chinese honey locust(S-2) were selected in the study. In addition, the foam is beneficial for improving the pumpability of wet-mix shotcrete. The foaming capacity and half-life period of two green foaming monomers were measured and the results are shown in Figure 3. Its dosage is marked as \% in the third section, meaning percentage of admixture relative to the $\mathrm{Ca}(\mathrm{OH})_{2}$ saturated solution (in weight).

According to Figure 3, increasing the concentration of both S-1 and S-2 about from $0 \%$ to $1.5 \%$ increased their foaming volume and also improved their half-life period of unload fluid in film. But it was evident that the foaming effect of S-1 was better than that of S-2 in both aspects of foaming volume and half-life period. And there was an optimum concentration for the foaming effect; S-1 was about $1.5 \%$ and S-2 was about $1.1 \%$. After the optimum point, the foaming volume stopped increasing, even decreasing slightly, especially for the trend of half-life period.

Analyzing the cause, the foaming capability is closely coupled with CPP (the surfactant critical packing parameter relative to the amount of surfactant). Theoretically speaking, the foaming ability should gradually increase with increasing 


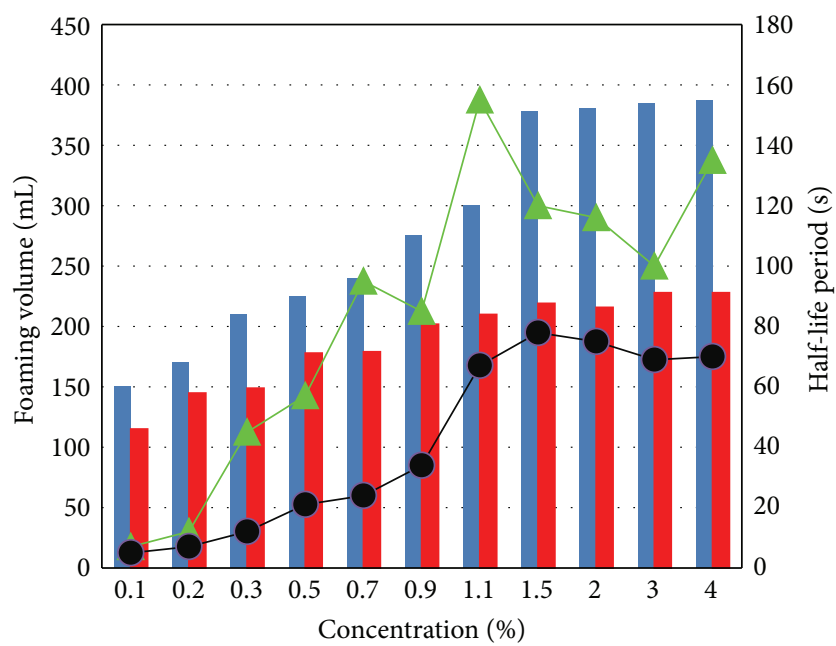

S-1 foaming volume S-2 foaming volume

- Half-life period of S-1 Half-life period of S-2

FIGURE 3: The foaming volume and half-life period of two monomers.

CPP. As the CPP increases, surfactants at the air-liquid surface pack together, forming the micelle, to give liquid film a good cohesion. This increases the surface viscosity and elasticity, hence resulting in a high foaming ability and stability. However, the holes are more easily formed and grow in the foam film where the CPP is large, due to thermal and mechanical fluctuations, which will break foam and cause a lower foaming ability. When the two phenomena balance each other, the foaming ability and stability will reach maximum [22]. The maximal foaming volume and half-life period of S-1 and S-2 were, respectively, $380 \mathrm{~mL}$ and $157 \mathrm{~s}$ and $220 \mathrm{~mL}$ and $78 \mathrm{~s}$. This also can be explained using the opinion of CMC (the critical micelle concentration), at higher CMC, only influencing the concentration of micelle, not increasing the surfactant monomer amount; hence the foaming volume would not improve [23].

Therefore, $1.5 \% \mathrm{~S}-1$ is good at foaming, but it did not reach up to the level of a conventional AEA in terms of foaming volume. Therefore, the optimization of foaming constituent was required to enhance the foaming volume.

3.1.2. Role and Selection of Suds Booster. In order to improve foaming volume, suds booster was selected to help S-1 generate more microbubbles for the synergy effect. Seven surfactants with different types were tested in the solution containing $1.5 \%$ S-1.

As shown in Figure 4, 1231 had the best foaming capacities owning the maximal foam volume and diameter in the mixed solution. In particular, the foaming volume of 1231 mixed with S-1 reached up to more than two times of other mixture systems. Although the two applications of AOS and OP-10 also presented the better film strength that showed relatively bigger foam diameter, their foaming volume was lesser. K12 and LAS, being excellent foaming monomers in distilled water, are easily effected by alkaline environment $[24,25]$, so

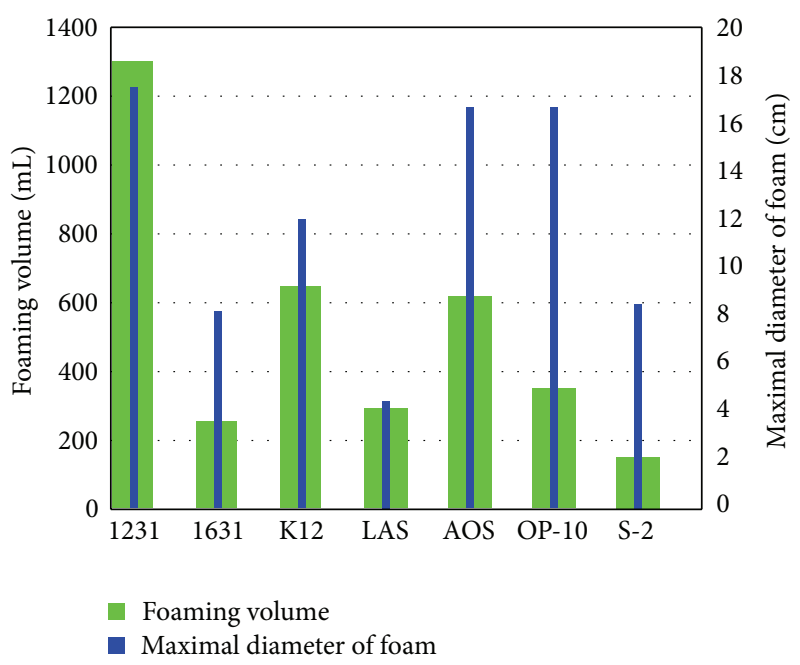

Figure 4: The synergistic effect of different surfactants with S-1.

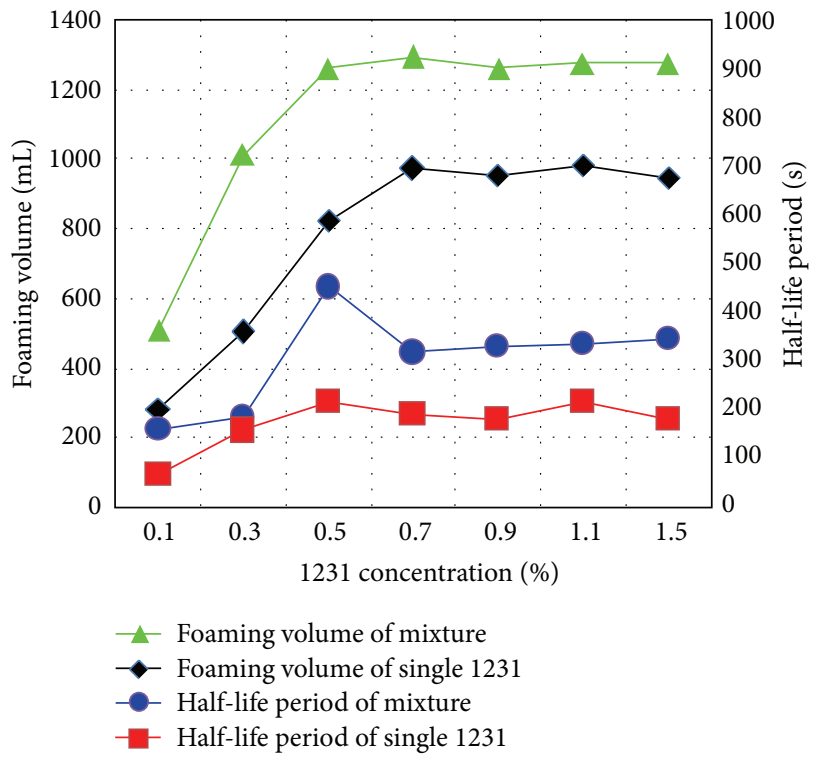

FIGURE 5: The foaming ability of single and mixture with 1231 concentration.

the synergistic effect of two mixtures is bad in the $\mathrm{Ca}(\mathrm{OH})_{2}$ solution. Therefore, 1231 was chosen as the suds booster of the air entraining formula.

To determine the optimal mix proportion between S-1 and 1231, further experiments investigated the foaming ability as a function of the concentration of 1231 ranging from $0.1 \%$ to $1.5 \%$ based on the solution mixed with and without $1.5 \%$ S-1. Results on the relationships between foaming volume, half-life period, and 1231 concentration are given in Figure 5. The mixed volume was obviously larger than the volume of single 1231, showing excellent complex synergism. With increasing continuously the concentration of 1231 , for mixed or single solution, the foaming volume and half-life period all increased and then declined slightly. Among the tests, $0.5 \%$ 1231 and over had the better foaming capacities; the $0.5 \% 1231$ 


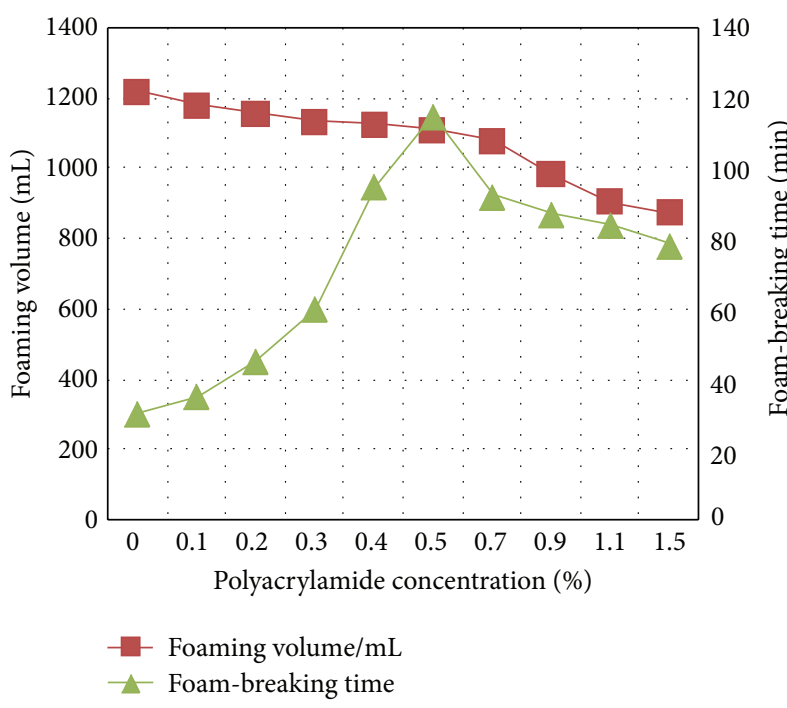

FIGURE 6: The influence of polyacrylamide on foaming volume and antifoam time.

mixed in the solution containing $1.5 \% \mathrm{~S}-1$ was the optimum concentration where the foaming ability reached maximum. Therefore, $0.5 \% 1231$ was selected. However, during the experiments, it was found that the foam would disappear sooner after $20 \mathrm{~min}$, which cannot meet the requirement for application in concrete engineering.

3.1.3. Determination of the Foaming Constituent $A$. To further enhance the foam stability and reduce the microbubble loss caused by the compelling forces from stirring and pumping, testing was conducted to optimize foaming constituent by combining with polyacrylamide. Polymer can induce surfactant aggregation and the reasonable polymer-surfactant system is beneficial for the foam stability [26]. Therefore, the amount of polyacrylamide added in the foaming constituent should be determined by experiments.

Various amounts of polyacrylamide were added to a solution containing $1.5 \% \mathrm{~S}-1$ and $0.5 \% 1231$ to test the effects in terms of foaming ability. After adding polyacrylamide, the foaming volume, being effected slightly, declined almost in linear fashion. However, it could be seen that the additive polyacrylamide effectively improved the foam life ranging from $0 \%$ to $0.5 \%$ and then decreased as shown in Figure 6, reaching the max life at the optimal concentration $0.5 \%$. But $0.5 \%$ polyacrylamide caused relatively big loss of foaming volume.

To further analyze the reason, the surface tension of the mixed solution was measured. Figure 7 shows that the surface tension declined sharply and then increased with increasing the amount of polyacrylamide. At low polymer concentrations, polymer associated with a few surfactants to form aggregation; thus most dissociative surfactants and few aggregations simultaneously existed in the solution where the surface tension was relatively big. With increasing polymer concentration, more and more polymers associated with the existing surfactant, up to CAC (the critical association concentration), about $0.3 \%$ polyacrylamide where the

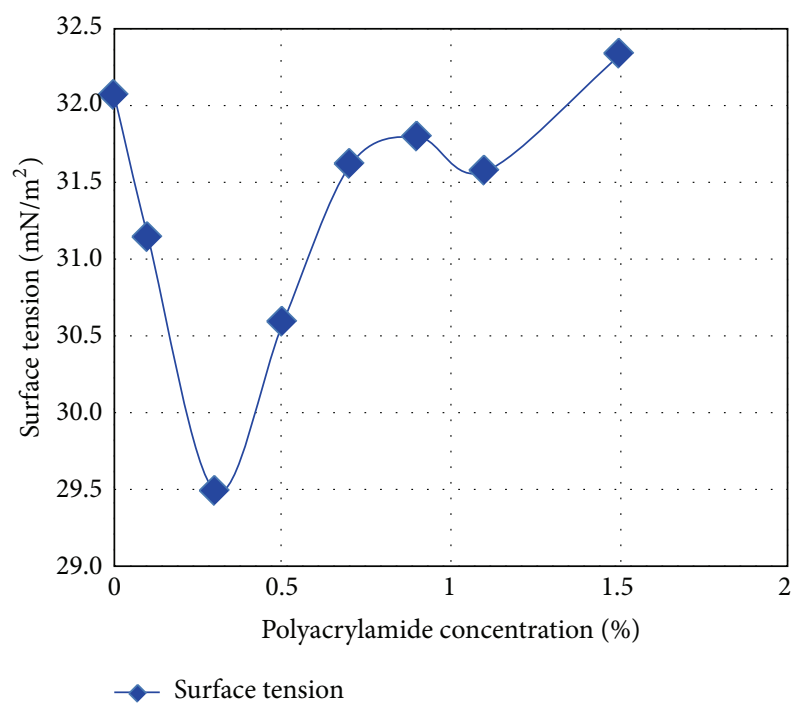

Figure 7: The change of surface tension with polyacrylamide.

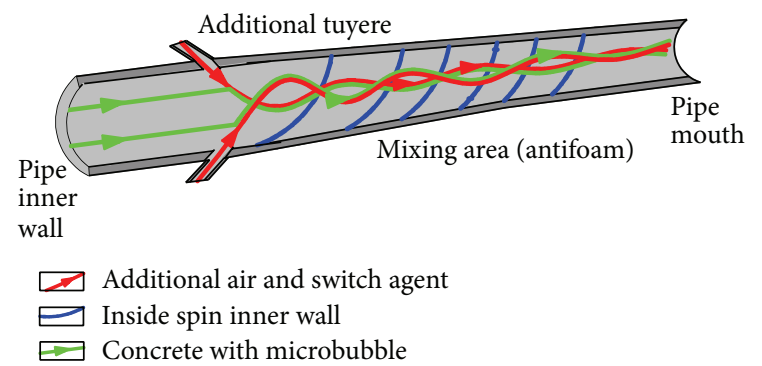

FIgURE 8: The scheme of mixing process of switch agent and foam concrete.

aggregation that can accelerate the formation of micelle at low surfactant concentration was dominant in the mixed solution and thus the surface tension reached a lowest value. Continuing adding polymer, the existing surfactant cannot meet the excess polymer to form enough aggregation, and redundant polymer dissociated in the solution, enhancing the viscosity of mixed solution. Hence, the surface tension increased and the foaming volume declined.

Studies above had shown that the addition of $0.3 \%$ polyacrylamide to a foaming agent can enhance the foam stability under the condition of low foam loss. Therefore, the optimal formula of foaming constituent A was 1.5\% S-1, 0.5\% 1231 , and $0.3 \%$ polyacrylamide.

3.2. Preparation of Switch Constituent B. High fluidity of wetmix shotcrete with a mass of microfoam may cause material dropping and waste the cost. Therefore, in order to reduce the fluidity of concrete sprayed on the wall, the switch agent used for defoaming was selected and added at the nozzle, that is, the entrance of compressed air, to decrease its fluidity and enhance the viscosity of concrete sprayed on the wall. Figure 8 shows the mixing process between concrete with microbubbles and switch constituent B under the action of high compressed air and insider spin inner pipe wall. 


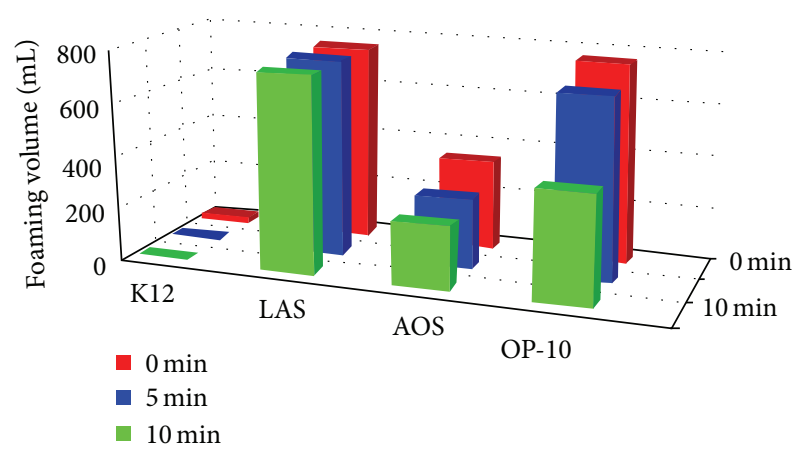

Figure 9: The synergistic effect of 1231 mixed with different anionic materials.

Although the surface tension of solution will decline because its surface activity becomes big after mixing cationic and anionic surfactants together, the improving acting force between micellar molecules, caused by cationic and anionic surfactants, may make it difficult to disperse micelle, reducing the number of surfactant monomers that will migrate to the new gas-liquid interface to help keep foaming. So the phenomenon of mixing cationic and anionic surfactants together may lead to low foaming capacity [27].

Given that the foaming constituent consisted of cationic surfactant and nonionic surfactant, in order to reach better antifoam effect, the anionic materials like K12, LAS, AOS, and OP-10, were selected as a part of switch antifoam agent that only aims at the 1231 cationic surfactant. Then, anionic materials were experimented with cationic surfactant 1231 at the same concentrations. Figure 9 shows the synergistic effect of 1231 mixed with different anionic materials. In the experiments, the antifoam effect of $\mathrm{K} 12$ was better than others, owning the lowest foam volume after mixing. There were few foams in mixed solution after $10 \mathrm{~min}$. Therefore, $\mathrm{K} 12$ was selected as an exclusive switch agent for 1231 cationic surfactant.

Further experiments were carried out in order to determine the optimal proportion of antifoam. Different K12 concentrations ranging from 0 to $1.1 \%$ were mixed in the solution containing $0.5 \% 1231$. Figure 10 shows that $0.5 \% \mathrm{~K} 12$ happened to present the best antifoam effect, the lowest foam volume up to $30 \mathrm{~mL}$.

Single K12 was not enough to remove all foams; hence silicone oil treated as one type of defoamer, reported in literature $[28,29]$, was selected as another switch antifoam agent that aims at all surfactants used for foaming. Silicone oil, ranging from 0 to $1.1 \%$, was added in the mother solution containing $1.5 \% \mathrm{~S}-1,0.5 \% 1231$, and 0.3 polyacrylamide. Figure 10 indicates that the foam volume decreased gradually with the increase of silicone oil. Considering that high speed concrete particles also break foam in the shooting process, $0.7 \%$ silicone oil was selected as an another switch antifoam agent. Therefore, the final switch constituent B included 0.5\% K12 and $0.7 \%$ silicone oil.

3.3. Formula of GSAE. According to the tested results, the final formula of GSAE was determined as shown in Table 1.

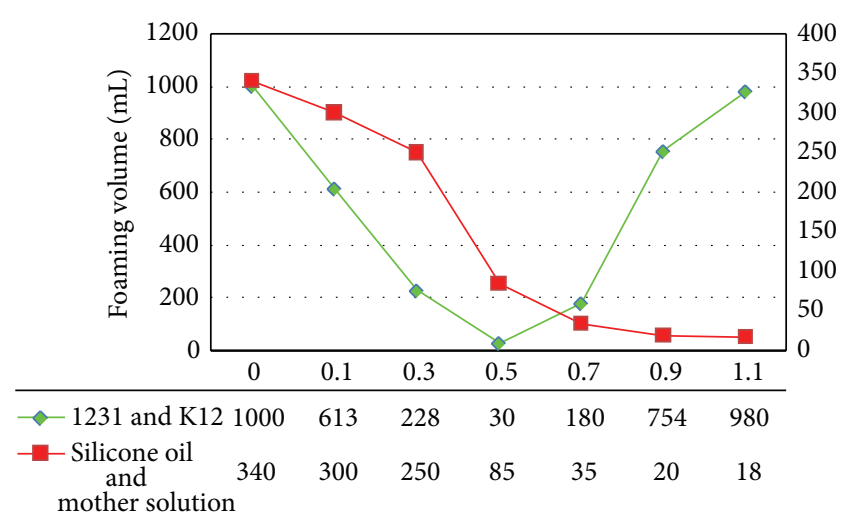

FIGURE 10: The effect of K12 against 1231 and silicone oil against mother solution.

TABLE 1: Mix proportion of GASE.

\begin{tabular}{lccccc}
\hline $\begin{array}{l}\text { Component of } \\
\text { GSAE }\end{array}$ & S-1 & 1231 & Polyacrylamide & K12 & $\begin{array}{c}\text { Silicone } \\
\text { oil }\end{array}$ \\
\hline $\begin{array}{l}\text { Mass content in } \\
\text { Ca(OH) } \\
\text { solution saturated }\end{array}$ & 1.5 & 0.5 & 0.3 & 0.5 & 0.7 \\
\begin{tabular}{l} 
Mix proportion \\
\hline
\end{tabular} & 1 & 0.33 & 0.2 & 0.33 & 0.47 \\
\hline
\end{tabular}

The new green switch air entraining agent used in wet-mix shotcrete contained two constituents of $\mathrm{A}$ and $\mathrm{B}$; into that matter, A was dry powder and B was solid-liquid mixture.

\section{Field Application Test}

4.1. Determination of the Optimum Mixing Amount. The main purpose of the research on GSAE was to improve the pumpability and shootability of wet-mix shotcrete, so the optimum mixing amount of GSAE should be determined by both requirements of pumpability and shootability. The traditional AEA cannot entrain too many microbubbles for avoiding strength loss, yet GSAE can entrain enough microbubbles due to the fact that the foam can be broken after adding switch agents at a nozzle. Therefore, the air content of concrete should not be measured; on the contrary, the performance of wet-mix shotcrete like slump and rebound rate, representing indirectly the pumpability and shootability, was measured for determining the optimal amount. According to the specified standard from GB8076-2008, the amount of AEA must be limited to make sure that the strength loss is kept in a certain range.

The established green switch air entraining agent was tested at an shotcreting site in the simulated roadway in Wit Laboratory Mine Equipment Co., Ltd. The mix proportions of wet-mix shotcrete are given in Table 2. The tested range of mixing amount of GSAE was presented at $0.05-0.3 \%$ according to the traditional AEA and the above experimental data $[30,31]$. Its dosage is marked as $\%$ in the fourth section, meaning percentage of admixture relative to cement (in weight). The amount of adding water was corrected to take 
TABLE 2: Mix proportion of wet-mix shotcrete with GSAE.

\begin{tabular}{lcccc}
\hline $\begin{array}{l}\text { Cement } \\
\left(\mathrm{kg} / \mathrm{m}^{3}\right)\end{array}$ & $\begin{array}{c}\text { Sand } \\
\left(\mathrm{kg} / \mathrm{m}^{3}\right)\end{array}$ & $\begin{array}{c}\text { Gravel } \\
\left(\mathrm{kg} / \mathrm{m}^{3}\right)\end{array}$ & W/C ratio & GSAE/\% \\
\hline 460 & 1100 & 720 & 0.4 & $0.05-0.3$ \\
\hline
\end{tabular}

TABLE 3: Mix proportion of tested wet-mix shotcrete.

\begin{tabular}{lcccccc}
\hline $\begin{array}{l}\text { Materials } \\
\text { number }\end{array}$ & $\begin{array}{c}\text { Cement } \\
\left(\mathrm{kg} / \mathrm{m}^{3}\right)\end{array}$ & $\begin{array}{c}\text { Sand } \\
\left(\mathrm{kg} / \mathrm{m}^{3}\right)\end{array}$ & $\begin{array}{c}\text { Gravel } \\
\left(\mathrm{kg} / \mathrm{m}^{3}\right)\end{array}$ & $\begin{array}{c}\text { W/C } \\
\text { ratio }\end{array}$ & 123A/\% GSAE/\% \\
\hline 1 & 460 & 1170 & 720 & 0.4 & & \\
2 & 460 & 1100 & 740 & 0.4 & 0.05 & \\
3 & 460 & 1100 & 740 & 0.4 & & 0.12 \\
\hline
\end{tabular}

into account the water absorbed by aggregates. The pipeline was equipped with two pressure sensors (model EP300, Xian Hehai Electronic Technology Co., Ltd., China). The first pressure sensor was located $5 \mathrm{~m}$ and the last one was located $15 \mathrm{~m}$ after the beginning of the pipeline.

Each concrete was produced by wet shotcrete units including both stirring and pumping. The mixing procedure was as follows: dry materials were mixed for $1 \mathrm{~min}$ and then water and foaming constituent $\mathrm{A}$ were added during the additional 2 min of mixing. Shortly after mixing, samples were taken and the fresh properties of initial slump and pressure bleeding rate were tested by means of the standard tests $[32,33]$. The pumping flow rate was set at $10 \mathrm{~m}^{3} / \mathrm{h}$.

The switch constituent $B$ was added at nozzle as shown in Figure 8. A plastic film was laid before spraying in the process, close to sprayed area. The material rebounded was collected and weighed after spraying. The one side of the simulated roadway was sprayed.

It is clear in Figure 11 that with the increase of GASE the slump improved and the rebound rate declined. This showed that the increase of GASE is beneficial for improving the pumpability and shootability of wet-mix shotcrete at a certain degree. And the strength loss met the specified standard. However, the $28 \mathrm{~d}$ compressive strength decreased slightly with increasing concentration of GSAE. Therefore, given the strength loss, the concentration of $0.1 \%-0.2 \%$ GSAE was selected such that it not only improves shotcrete fluidity and viscosity but also guarantees better strength.

4.2. Comparative Analysis. To verify the effect of the optimal formula, a comparative analysis was conducted using a conventional type AEA, called 123A, in terms of pumpability including slump, bleeding rate, and pressure loss and shootability including rebound rate and the depth of one shotcrete layer. Wet-mix shotcretes with and without AEA were studied in this work. Their mix proportions are given in Table 3.

4.2.1. Comparative Analysis of Pumpability. The data in Table 4 shows that application of 123A or GSAE obviously improved the fresh concrete pumpability. GSAE was slightly superior to the $123 \mathrm{~A}$ in terms of improving slump, reducing pipe pressure loss, and the rate of pressure bleeding. The GSAE achieved better pumpability effects, validating the

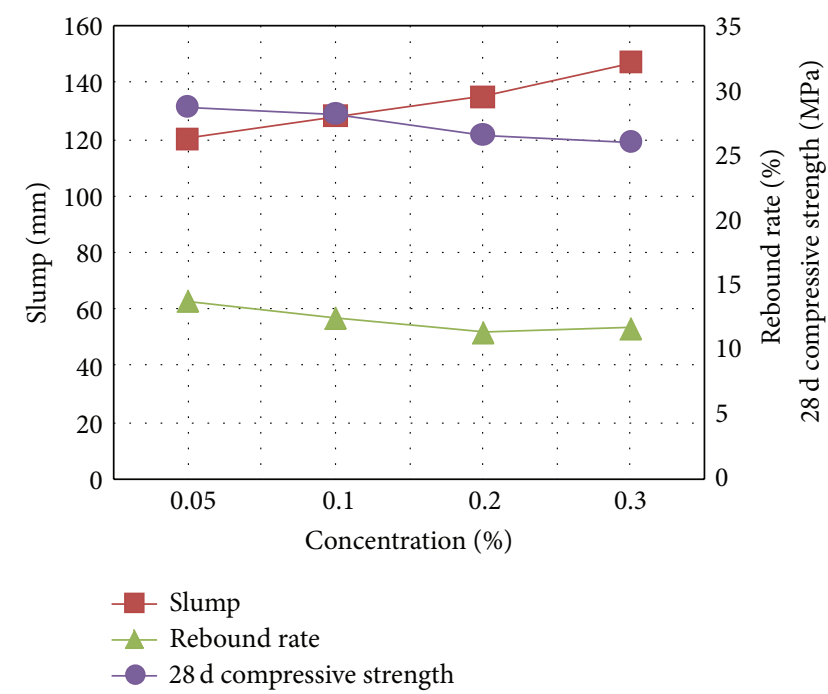

FIGURE 11: The performance of wet-mix shotcrete with various GSAE concentration.

TABLE 4: The pumpability comparison of different wet-mix shotcretes.

\begin{tabular}{lccc}
\hline Number & Slump/mm & $\begin{array}{c}\text { Pressure loss } \\
(\mathrm{MPa} / \mathrm{m})\end{array}$ & $\begin{array}{c}\text { Rate of pressure } \\
\text { bleeding/\% }\end{array}$ \\
\hline 1 & 90 & 0.032 & 22.4 \\
2 & 120 & 0.021 & 17.5 \\
3 & 125 & 0.018 & 14.3 \\
\hline
\end{tabular}

TABLE 5: The shootability comparison of different wet-mix shotcretes.

\begin{tabular}{lccc}
\hline Number & $\begin{array}{c}\text { Average } \\
\text { rebound rate/\% }\end{array}$ & $\begin{array}{c}\text { Depth of one } \\
\text { shotcrete } \\
\text { layer/mm }\end{array}$ & $\begin{array}{c}\text { 28 d compressive } \\
\text { strength (MPa) }\end{array}$ \\
\hline 1 & 15.3 & 15.2 & 28.6 \\
2 & 16.8 & 11.7 & 24.3 \\
3 & 13.7 & 16.5 & 27.9 \\
\hline
\end{tabular}

lubrication and ball effect of microbubbles generated by foaming constituent $\mathrm{A}$. The average slump in the shotcreting site was improved from $90 \mathrm{~mm}$ in case of not adding AEA and $120 \mathrm{~mm}$ in case of adding $123 \mathrm{~A}$ to $125 \mathrm{~mm}$ using GSAE. The average pipe pressure loss reduced from $0.032 \mathrm{MPa} / \mathrm{m}$ and $0.021 \mathrm{MPa} / \mathrm{m}$ to $0.018 \mathrm{MPa} / \mathrm{m}$. The average rate of pressure bleeding reduced from $22.4 \%$ and $17.5 \%$ to $14.3 \%$.

4.2.2. Comparative Analysis of Shootability. The data in Table 5 shows the following:

(1) The sequence of rebound rate was $123 \mathrm{~A}>$ without adding AEA > GSAE, which suggested that the switch antifoam constituent in GSAE played a key role in reducing the rebound rate of wet spraying concrete when compared with traditional AEA. In particular, the rebound rate of wet shotcrete that employed 123A or lacked an AEA did not meet the requirement of 
national standard GB50086-2001 that the rebound rate at the sides should be less than $15 \%$. The polyacrylamide as a foam stabilizer in GSAE improved the viscosity of mixture after defoaming, so the rebound rate of shotcrete with GSAE is lower than that without AEA.

(2) The average depth of one shotcrete layer with the addition of GSAE was $16.5 \mathrm{~mm}$ more than that with the addition of 123A, and GSAE effectively improved the depth of one shotcrete layer; therefore, it showed that the switch agent had succeeded in removing microbubble for reducing concrete fluidity on the wall.

(3) According to national standard GB50086-2001, the $28 \mathrm{~d}$ compressive strength of shotcrete was measured. As it can be seen from the data in Table 5, when AEA was included in the shotcrete, the $28 \mathrm{~d}$ compressive strength generally decreased. The $28 \mathrm{~d}$ compressive strength loss of $123 \mathrm{~A}$ was biggest due to a lot of microbubble that were entrained in concrete. There was less loss in terms of $28 \mathrm{~d}$ compressive strength when adding GSAE because the microbubble existing in concrete was almost broken by the switch agent. This met the requirements of $20 \mathrm{MPa}$ outlined in GB50086-2001.

\section{Conclusions}

The paper developed a new type of green switch air entraining agent (GSAE) and proposed its application method for wetmix shotcrete, which can improve both the pumpability and shootability. The GSAE contained two constituents A and B. A constituent, used for entraining microbubbles to improve pumpability, was premixed with fresh concrete. B constituent, used for breaking foam to reduce fluidity, was added at nozzle. Through extensive experimental testing, we selected Sapindus mukorossi(S-1) as the main foaming material, dodecyl trimethyl ammonium chloride(1231) as the suds booster, polyacrylamide as the stability agent, and both lauryl sodium sulfate and silicone oil as the switch constituent. The mass mix proportion was $\mathrm{S}-1: 1231$ : polyacrylamide $: \mathrm{K} 12:$ silicone oil = $1: 0.33: 0.2: 0.33: 0.47$.

The performance of GSAE was measured according to national standard GB8076-2008 (Concrete Admixture) and GB50086-2001 (Specifications for Bolt-Shotcrete Support). Experimental investigation showed that the optimal mixing amount of GSAE was $0.1 \%-0.2 \%$ relative to cement. The slump of wet-mix shotcrete with the $0.12 \%$ GSAE was $125 \mathrm{~mm}$, the pipeline pressure loss was $0.018 \mathrm{MPa} / \mathrm{m}, 28 \mathrm{~d}$ compressive strength was $27.9 \mathrm{MPa}$, the average rebound rate was 13.7, and the depth of one shotcrete layer was $16.5 \mathrm{~mm}$, all of which met the first-grade product requirements of the China National Standard. The comparative tests at a shotcreting site in the simulated roadway in Wit Laboratory Mine Equipment Co., Ltd. showed that GSAE outperformed conventional AEA in terms of pumpability and $28 \mathrm{~d}$ compressive strength, especially shootability.

\section{Competing Interests}

The authors declare that there are no competing interests regarding the publication of this paper.

\section{Acknowledgments}

This work was financially supported by National Natural Science Foundation of China (Grant no. 51404145); Natural Science Foundation of China of Shandong province (Grant no. ZR2013EEQ021); Applied Research Project Foundation of Qingdao Postdoctoral Researcher (Grant no. 2015176); Open Fund of the State Key Laboratory of Mining Disaster Prevention and Control Co-Founded by Shandong Province and the Ministry of Science and Technology (Grant no. MDPC2012ZR02).

\section{References}

[1] N. Ginouse, M. Jolin, and B. Bissonnette, "Effect of equipment on spray velocity distribution in shotcrete applications," Construction and Building Materials, vol. 70, pp. 362-369, 2014.

[2] N.-I. Vatin, G.-Y. Barabanshchikov, M.-V. Komarinskiy, and S.I. Smirnov, "Modification of the cast concrete mixture by airentraining agents," Magazine of Civil Engineering, vol. 56, no. 4, pp. 3-10, 2015.

[3] A. Öztaş, M. Pala, E. Özbay, E. Kanca, N. Çağlar, and M. A. Bhatti, "Predicting the compressive strength and slump of high strength concrete using neural network," Construction and Building Materials, vol. 20, no. 9, pp. 769-775, 2006.

[4] Y. Jiang, Z. Xu, F. Li, and G. Li, "Engineering performance of polycarboxylate based air entraining agent," Journal of Southeast University (Natural Science Edition), vol. 36, no. 4, pp. 568-571, 2006.

[5] Y. Barabanshchikov and M. Komarinskiy, "Effect of airentraining agent LHD on the technological properties of concrete mix containing superplasticizer S-3," Applied Mechanics and Materials, vol. 725-726, pp. 419-424, 2015.

[6] E. K. Attiogbe, "Predicting freeze-thaw durability of concretea new approach," ACI Materials Journal, vol. 93, no. 5, pp. 457464, 1996.

[7] M. Pigeon and R. Pleau, Durability of Concrete in Cold Climates, 1997.

[8] K.-K. Yun, S.-Y. Choi, and J. H. Yeon, "Effects of admixtures on the rheological properties of high-performance wet-mix shotcrete mixtures," Construction and Building Materials, vol. 78, pp. 194-202, 2015.

[9] G.-H. Tattersall and P. Banfill, The Rheology of Fresh Concrete, Pitman Advanced Publishing Program, London, UK, 1983.

[10] P. V. den Heede, J. Furniere, and N. D. Belie, "Influence of air entraining agents on deicing salt scaling resistance and transport properties of high-volume fly ash concrete," Cement and Concrete Composites, vol. 37, no. 1, pp. 293-303, 2013.

[11] G. Albayrak, M. Canbaz, and U. Albayrak, "Statistical analysis of chemical admixtures usage for concrete: a survey of eskisehir city, turkey," Procedia Engineering, vol. 118, pp. 1236-1241, 2015.

[12] Å. C. Andersson and A.-M. Stromvall, "Leaching of concrete admixtures containing thiocyanate and resin acids," Environmental Science and Technology, vol. 35, no. 4, pp. 788-793, 2001. 
[13] State Administration of Traditional Chinese Medicine, The Chinese Materia Medica, Editorial Board, Shanghai Scientific and Technical Publishers, Shanghai, China, 1999.

[14] S. Song, L. Zhu, and W. Zhou, "Simultaneous removal of phenanthrene and cadmium from contaminated soils by saponin, a plant-derived biosurfactant," Environmental Pollution, vol. 156, no. 3, pp. 1368-1370, 2008.

[15] D. Roy, R.-R. Kommalapati, S.-S. Mandava, K.-T. Valsaraj, and W.-D. Constant, "Soil washing potential of a natural surfactant," Environmental Science \& Technology, vol. 31, no. 3, pp. 670-675, 1997.

[16] S. Mukhopadhyay, S. Mukherjee, M. A. Hashim, and B. S. Gupta, "Application of colloidal gas aphron suspensions produced from Sapindus mukorossi for arsenic removal from contaminated soil," Chemosphere, vol. 119, pp. 355-362, 2015.

[17] Q. Yang, P. Zhu, S. Huang, and X. Wu, "Research report on saponin-based air-entraining agent," Tech. Rep. 98-8, The Research Laboratory of Materials Engineering, Tongji University, Shanghai, China, 1998.

[18] Q. Yang, P. Zhu, X. Wu, and S. Huang, "Properties of concrete with a new type of saponin air-entraining agent," Cement and Concrete Research, vol. 30, no. 8, pp. 1313-1317, 2000.

[19] R. Bordes and K. Holmberg, "Amino acid-based surfactantsdo they deserve more attention?" Advances in Colloid and Interface Science, vol. 222, pp. 79-91, 2015.

[20] W. Wang, W. Lu, and L. Jiang, "Influence of $\mathrm{pH}$ on the aggregation morphology of a novel surfactant with single hydrocarbon chain and multi-amine headgroups," The Journal of Physical Chemistry B, vol. 112, no. 5, pp. 1409-1413, 2008.

[21] R. Zhu and S. Wu, "Development of concrete air entraining agent of plant source to improve the combination property of concrete," in Proceedings of the Concrete Admixture and Its Application Technology Conference, 2004.

[22] R. Aveyard, "Defoaming. Theory and industrial applications," Journal of Chemical Technology AND Biotechnology, vol. 59, no. 1, pp. 114-115, 1994.

[23] R. Rajagopalan, "Review of the colloidal domain: where physics, chemistry, biology, and technology meet, by D. Fennell Evans and Håkan Wennerström," Journal of Colloid and Interface Science, vol. 172, no. 2, p. 541, 1995.

[24] M. Sreenu, R. R. Nayak, R. B. N. Prasad, Y. Poornachandra, and C. G. Kumar, "Surface and antimicrobial properties of $\mathrm{N}$ palmitoyl amino acid-based surfactants," Journal of Dispersion Science and Technology, vol. 36, no. 6, pp. 765-771, 2015.

[25] Z. H. Zhu, D. Yang, and M. J. Rosen, "Some synergistic properties of N-Alkyl- $\alpha$-pyrrolidones, a new class of surfactants," Journal of the American Oil Chemists' Society, vol. 66, no. 7, pp. 998-1001, 1989.

[26] J. Martinez-Santiago, K. P. Ananthapadmanabhan, L. Tsaur, C. Totland, and P. Somasundaran, "Effects of fatty acids on polyelectrolyte-surfactant interactions: implications for polymer-induced flocculation/dispersion in emulsion systems," Colloids and Surfaces A: Physicochemical and Engineering Aspects, vol. 461, no. 1, pp. 57-65, 2014.

[27] G. Li and X. Zhao, "Molecular interaction and phase-sepration in the aqueous solution of anionic-cationic surfactant mixture," Acta Physico Chimica Sinica, vol. 11, no. 5, pp. 450-453, 1995.

[28] B. Sithole and C. Watanabe, "Using Py-GC/MS to detect and measure silicone defoamers in pulp fibres and mill deposits," Journal of Analytical and Applied Pyrolysis, vol. 103, pp. 8-16, 2013.
[29] T. Tamura, M. Kageyama, Y. Kaneko, T. Kishino, and M. Nikaido, "Direct observation of foam film rupture by several types of antifoams using a scanning laser microscope," Journal of Colloid and Interface Science, vol. 213, no. 1, pp. 179-186, 1999.

[30] L. Du and K. J. Folliard, "Mechanisms of air entrainment in concrete," Cement and Concrete Research, vol. 35, no. 8, pp. 1463-1471, 2005.

[31] P. Choi, J.-H. Yeon, and K.-K. Yun, "Air-void structure, strength, and permeability of wet-mix shotcrete before and after shotcreting operation: the influences of silica fume and air-entraining agent," Cement and Concrete Composites, vol. 70, pp. 69-77, 2016.

[32] D. Feys, R. Verhoeven, and G. De Schutter, "Fresh self compacting concrete, a shear thickening material," Cement and Concrete Research, vol. 38, no. 7, pp. 920-929, 2008.

[33] M. A. R. Bhutta, K. Tsuruta, and J. Mirza, "Evaluation of highperformance porous concrete properties," Construction and Building Materials, vol. 31, pp. 67-73, 2012. 

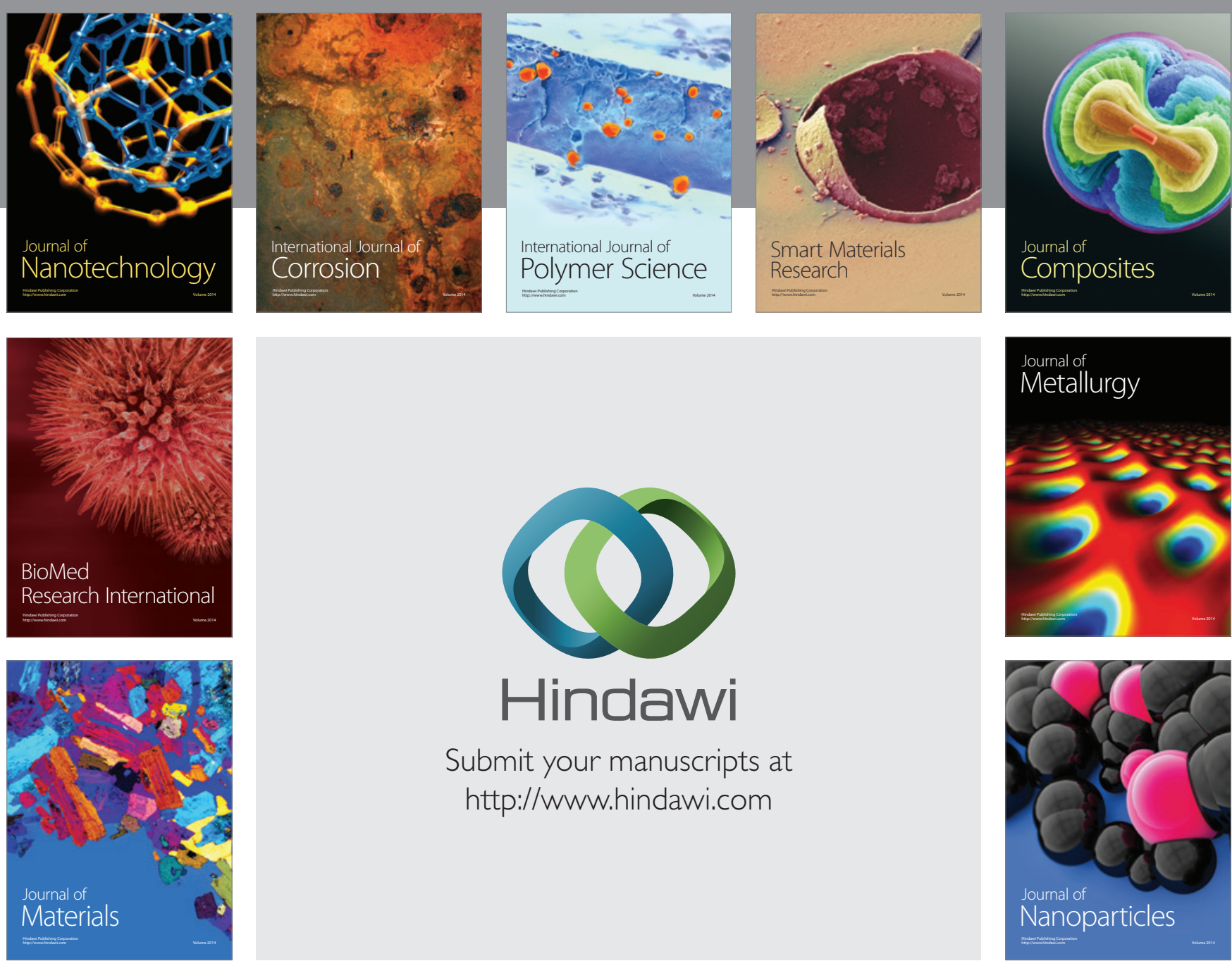

\section{Hindawi}

Submit your manuscripts at

http://www.hindawi.com

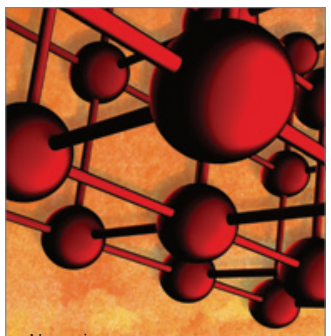

Materials Science and Engineering
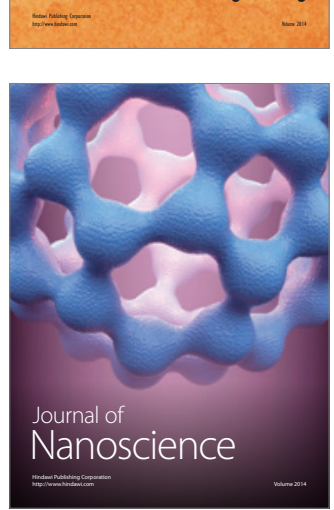
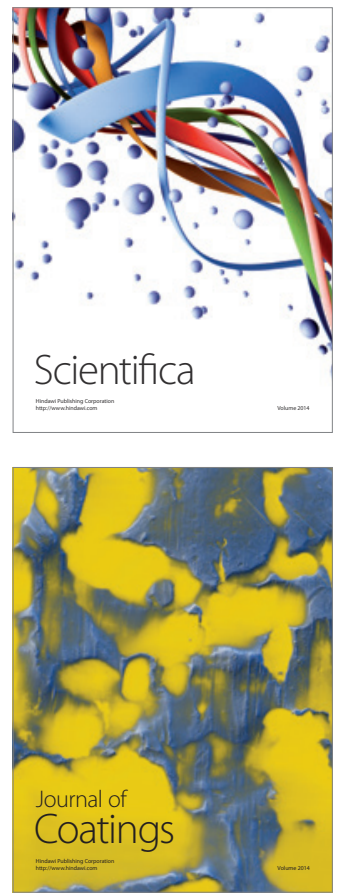
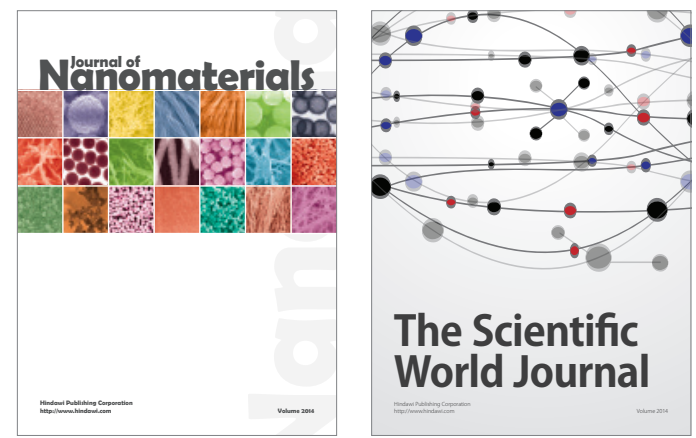

The Scientific World Journal
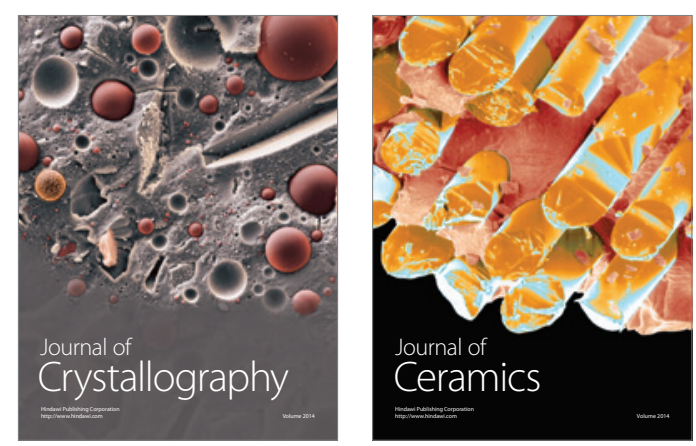
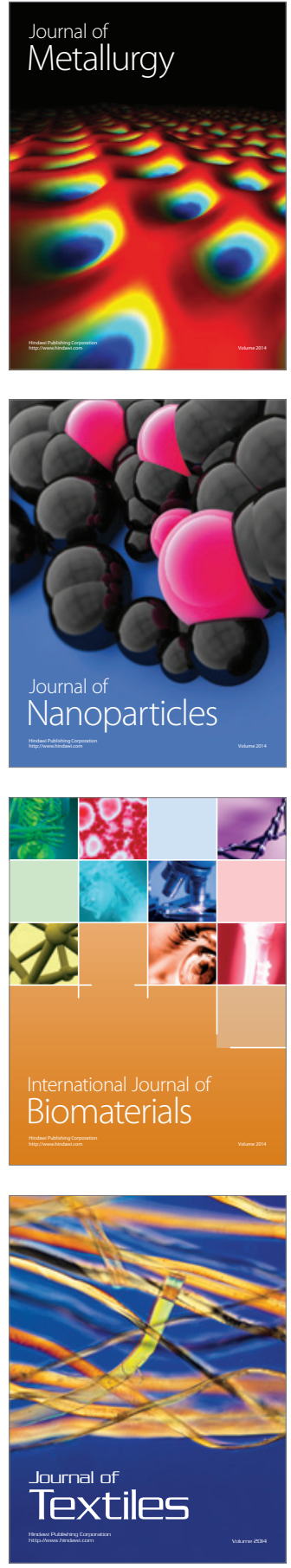